\title{
Impacts of changes in vegetation cover on soil water heat coupling in an alpine meadow of the Qinghai-Tibet Plateau, China
}

\author{
W. Genxu ${ }^{1,2}$, H. Hongchang ${ }^{2}$, L. Guangsheng ${ }^{2}$, and L. Na ${ }^{1}$ \\ ${ }^{1}$ Institute of Mountain Hazards and Environment, Chinese Academy of Sciences, Chengdu 610041, China \\ ${ }^{2}$ College of Resources \& Environment, Lanzhou University, Lanzhou 730000, China
}

Received: 4 August 2008 - Published in Hydrol. Earth Syst. Sci. Discuss.: 4 September 2008

Revised: 24 February 2009 - Accepted: 3 March 2009 - Published: 13 March 2009

\begin{abstract}
Alpine meadow is one of the most widespread grassland types in the permafrost regions of the QinghaiTibet Plateau, and the transmission of coupled soil water heat is one of the most crucial processes influencing cyclic variations in the hydrology of frozen soil regions, especially under different vegetation covers. The present study assesses the impact of changes in vegetation cover on the coupling of soil water and heat in a permafrost region. Soil moisture $\left(\theta_{v}\right)$, soil temperature $\left(T_{s}\right)$, soil heat content, and differences in $\theta_{v}-T_{S}$ coupling were monitored on a seasonal and daily basis under three different vegetation covers $(30,65$, and $93 \%$ ) on both thawed and frozen soils. Regression analysis of $\theta_{v}$ vs. $T_{s}$ plots under different levels of vegetation cover indicates that soil freeze-thaw processes were significantly affected by the changes in vegetation cover. The decrease in vegetation cover of an alpine meadow reduced the difference between air temperature and ground temperature $\left(\Delta T_{a-s}\right)$, and it also resulted in a decrease in $T_{s}$ at which soil froze, and an increase in the temperature at which it thawed. This was reflected in a greater response of soil temperature to changes in air temperature $\left(T_{a}\right)$. For $\Delta T_{a-s}$ outside the range of -0.1 to $1.0^{\circ} \mathrm{C}$, root zone soil-water temperatures showed a significant increase with increasing $\Delta T_{a-s}$; however, the magnitude of this relationship was dampened with increasing vegetation cover. At the time of maximum water content in the thawing season, the soil temperature decreased with increasing vegetation. Changes in vegetation cover also led to variations in $\theta_{v}-T_{s}$ coupling. With the increase in vegetation cover, the surface heat flux decreased. Soil heat storage at $20 \mathrm{~cm}$ in depth increased with increasing vegetation cover, and the heat flux that was downwardly transmitted de-
\end{abstract}

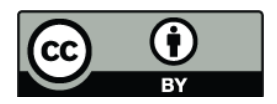

Correspondence to: W. Genxu (wanggx@imde.ac.cn) creased. The soil property varied greatly under different vegetation covers, causing the variation of heat conductivity and water-heat hold capacity in topsoil layer in different vegetation cover. The variation of heat budget and transmitting in soil is the main factor that causes changes in soil thawing and freezing processes, and $\theta_{v}-T_{S}$ coupling relationship under different vegetation fractions. In addition to providing insulation against soil warming, vegetation in alpine meadows within the permafrost region also would slow down the response of permafrost to climatic warming via the greater water-holding capacity of its root zone. Such vegetation may therefore play an important role in conserving water in alpine meadows and maintaining the stability of engineering works constructed within frozen soil of the Qinghai-Tibet Plateau.

\section{Introduction}

Global climate change has a significant effect on natural ecosystems in many regions of the world. Frost or permafrost ecosystems are defined as cold, high-altitude environments within alpine or high-latitude regions, in which freeze-thaw cycles lead to temporal variations in the quantity of soil water and heat (Wu et al., 2002; Walker et al., 2003). The frost ecosystems are arguably among the most sensitive to the climate change because of the sensitivity of the permafrost environment to climate warming (Walker et al., 2003; Christensen et al., 2004). Changes in vegetation cover of these ecosystems lead to dramatic changes in the physical properties of the soil, the dynamics of the surface soil water, and the soil carbon cycle, which in turn exert a profound influence on the entire biosphere (Weller et al., 1995; Jorgenson et al., 2001; Christensen et al., 2004). Given the magnitudes of the heat sinks within frost regions, the terrestrial ecosystems of

Published by Copernicus Publications on behalf of the European Geosciences Union. 


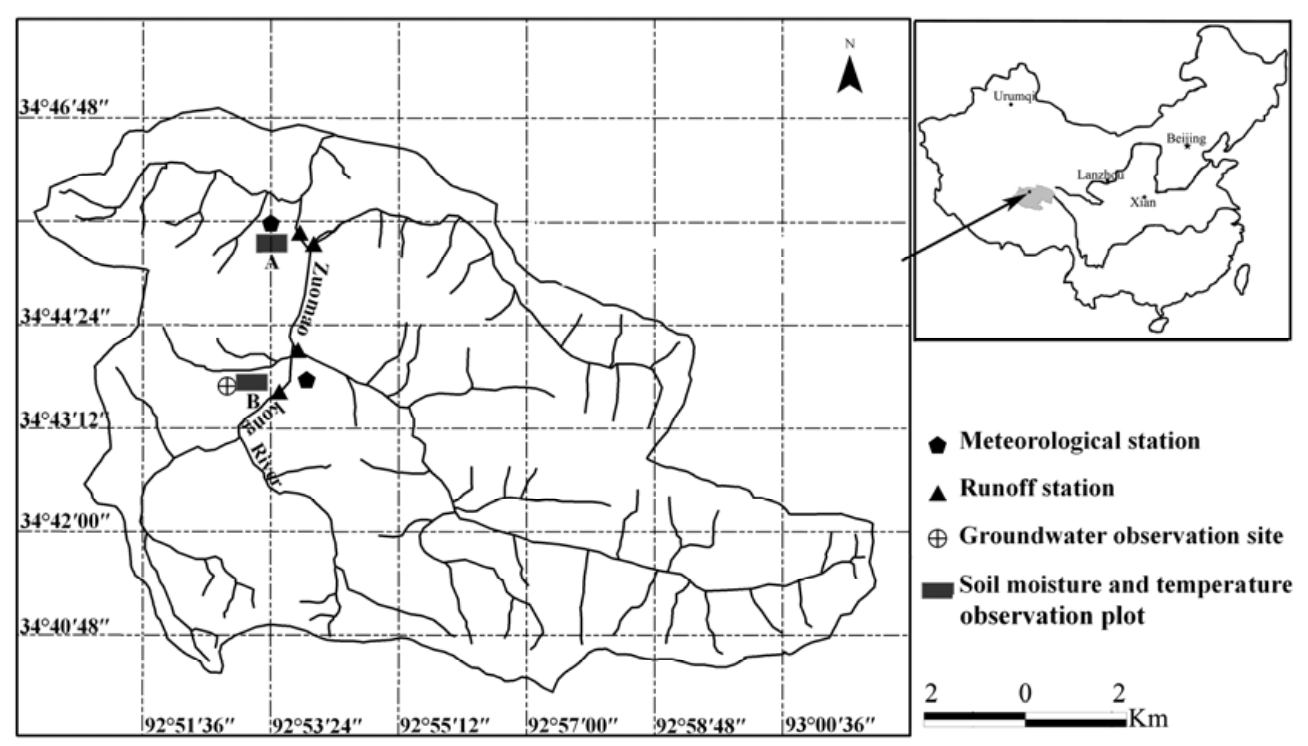

Fig. 1. Location of the study area.

cold regions exert a strong influence on the water cycle and the heat balance of regional land-atmosphere systems (Carey and Woo, 1999; Rouse, 2000). Consequently, the energy and water balance of the Qinghai-Tibet Plateau has an important influence on the Asian monsoon system, making it an essential component of energy and water cycles of the global climate (Zhang et al., 2003). Accordingly, a significant response of the alpine frost ecosystems on the Qinghai-Tibet Plateau to global climate change would have a substantial feedback on global climate.

Shifts in energy and water balance causing by a response of the permafrost region's alpine frost ecosystems to global climate change would most likely be reflected in the changes of moisture and the associated heat of the permafrost soil. Therefore, knowledge of the laws that govern the variations in soil moisture and the associated heat of alpine frost ecosystems are important to understand the regional variations in water cycling that arise from the global climate changes (Rouse, 2000; Zhang et al., 2003). Increasing interests have been generated in the role of permafrost in water and heat cycles, including studies on hydrological processes in the Mackenzie Global Energy and Water Cycle Experiment (Rouse, 2000) and the role of permafrost in hydrological processes within North American subarctic wetland (Oechel et al., 2000; Carey and Woo, 1999). Investigations in subarctic Canada and Alaska found that climate change had led to an increase in the topsoil moisture content of the permafrost region (Jorgenson et al., 2001; Turetsky et al., 2002). However, studies in other regions (e.g., northern Alaska) reported reduced topsoil moisture content and even drought (Christensen et al., 2004). Besides that, Zhang et al. (2005) found that the soil temperature, soil water cycle and energy balance varied significantly under different vegetation types such as forest and grassland at the edge of the Eurasian cryosphere. Yi et al. (2007) pointed out that surface cover condition play a dominant role in affecting ground thaw by using the CLM3 model simulations. Thus, permafrost degradation under climate warming can affect processes such as surface water and energy flux, and plant-development processes in tundra regions (Jayawickreme et al., 2008). However, the dynamic interactions between vegetation and active soil temperature remain largely unresolved because it is difficult to quantify the variation in soil texture and hydrological flux under different vegetation types and structures (Bakalin and Vetrova, 2008; Jayawickreme et al., 2008). Further studies in different regions are necessary to ascertain the laws governing water cycling within the permafrost-vegetation-atmosphere system, and its influence on global climate change (Bubier et al., 1999; Oeche et al., 2000; Christensen et al., 2004).

The alpine meadows constitute the main land type of the permafrost region of the Qinghai-Tibet Plateau. They are located in the source areas of several large rivers, including the Yangtze and Yellow Rivers, and therefore play an important role in regulating river flow and the productivity of local grazing grasslands (Zhou, 2001; Wang et al., 2001a). In the past 30 years, $24 \%$ decline in the extent of high-coverage (vegetation cover in excess of $85 \%$ ) alpine meadows had been observed in this region, indicating a serious ecosystem degradation (Wang et al., 2004; Yang et al., 2005). To understand the mechanism of the variations in soil moisture and the associated heat of alpine frost ecosystems and the impacts of climate changes on alpine frost ecosystems and permafrost in Qinghai-Tibet Plateau, it is important to identify the variation in soil heat-water coupling associated with alpine vegetation cover changes. Despite extensive researches on this topic, current observation data are not sufficient to reach a 
consensus on the active soil water-heat coupling variation under alpine vegetation cover changes in the Qinghai-Tibet permafrost regions (Zhang et al., 2003; Zhou, 2000; Wang et al., 2007). Therefore, the objectives of the present study are to document the basic characteristics of changes in water and heat dynamics under different degrees of cover degradation in alpine meadows of the permafrost region, and to analyze the possible effects of vegetation within alpine meadows on the active soil water heat coupling relationship.

\section{Study area}

The study area is conducted in the watershed of the Zuomao Kong River, a second-order tributary of the Yangtze River located in the eastern permafrost region of the Qinghai-Tibet Plateau $\left(92^{\circ} 50^{\prime}-93^{\circ} 3^{\prime} \mathrm{E}, 34^{\circ} 40^{\prime}-34^{\circ} 48^{\prime} \mathrm{N}\right)$. The watershed occupies a total area of $127.63 \mathrm{~km}^{2}$ and elevations ranging from 4510 to $4723 \mathrm{~m}$ above sea level (Fig. 1). The area is part of the headwater region of the Yangtze River, and Bordered by the Tanggula Mountains in the south and the Kunlun-Bayan Har Mountains in the north. The study region has a population of 246 (2005), who are mainly Tibetan and pastoralists, and livestock grazing is the main economic activity.

\subsection{Vegetation, soil and permafrost}

Vegetation in the area is dominated by Kobresia pygmaea C. B. Clarke and Kobresia humilis Serg. Monthly average normalized difference vegetation index (NDVI, Normalized Difference Vegetation Index) began to increase from 0.2 in late April, reached a maximum of 0.7 in August, and then decreased to 0.4 in October. Leaf area index (LAI) increased consistently from late May, reaching a maximum of 5.2 in late July, and then decreased slowly thereafter (Yang et al., 2005). According to the degree of degradation, vegetation cover in the region's grasslands is divided into three categories: non-degraded, moderately degraded, and severely degraded, corresponding to $93 \%, 65 \%$ and $30 \%$ coverage, respectively. In severely degraded grassland, Kobresia $s p$. is replaced by Festuca sp. and Poa spp. (Wang et al., 2001b; Zhou, 2001). The single vegetation type with different degradation degree grassland distribution is favourable to the aim of this study.

Based on the data from China's second national soil survey (NSSO, 1998), the soil types in the study region were mainly classified as Mattic Cryic Cambisols (Alpine meadow soil) in Chinese taxonomy, or as Cambisols in FAO/UNESCO taxonomy. With the most significant characteristic being that there is Mattic epipedon (Oo) in Alpine meadow soil. Table 1 lists the main physical properties and nutrient contents of the region's alpine meadow soils under different levels of cover. In severely degraded alpine meadows, the amount of coarse sand and gravel within the topsoil was significantly higher
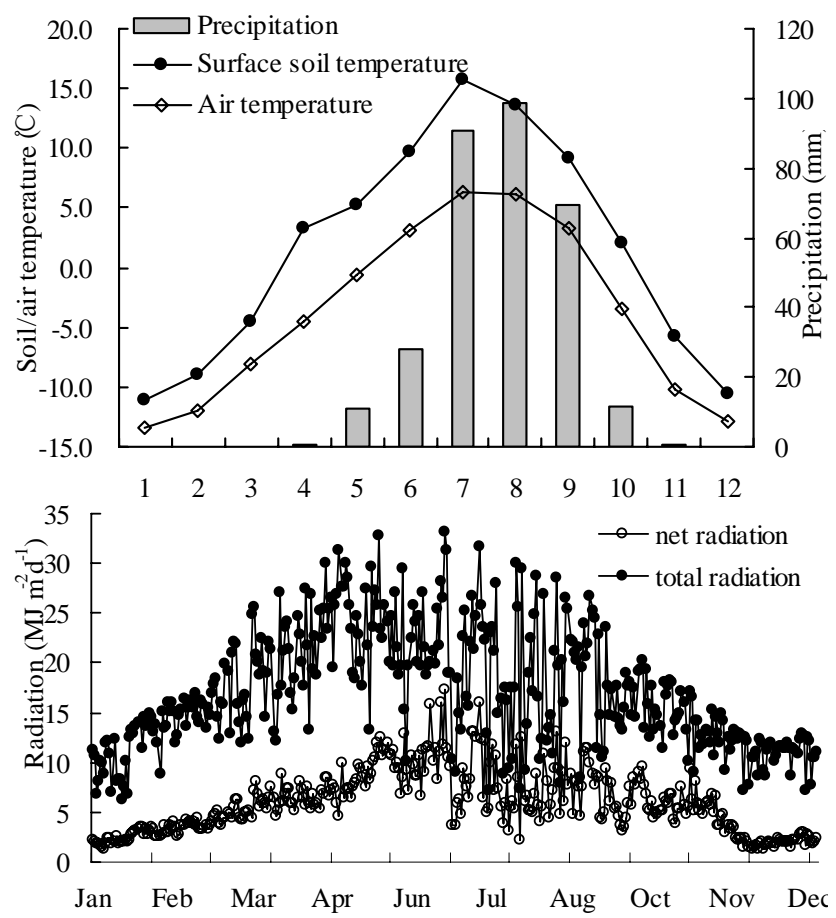

Fig. 2. Monthly precipitation, air temperature and soil temperature at $5 \mathrm{~cm}$ in depth (a); Monthly total radiation and net radiation (b).

than that in non-degraded areas. Soil organic matter content (SOM) in the $0-0.2 \mathrm{~m}$ soil layer (root zone) declined significantly with increasing degradation of vegetation cover: for a decline in cover from 93 to $30 \%$, SOM falls from 13.6 to $4.5 \mathrm{~g} \mathrm{~kg}^{-1}$, along with a corresponding $44 \%$ reduction in total $\mathrm{N}$ content.

Permafrost is well developed in the study area, averaging between 70 and $120 \mathrm{~m}$ in depth, with an active layer of $0.8-1.5 \mathrm{~m}$ and permafrost temperature of between -1.5 and $-3.7^{\circ} \mathrm{C}$ with a thick layer of ground ice (Zhou et al., 2000). The ground starts to thaw in mid April and thaws to a maximum depth (about $150 \mathrm{~cm}$ ) in late August. The surface starts to freeze around mid October and the entire active layer is frozen by about late November. The mean annual permafrost surface temperature increased with a mean ratio of $0.06^{\circ} \mathrm{C}$ per year from 1990 to 2001 (Wu and Liu, 2004).

\subsection{Climatic condition}

The annual mean air temperature $\left(T_{a}\right)$, relative humidity, and precipitation between 1973 and 2005 are $-5.2^{\circ} \mathrm{C}, 57 \%$, and $310.7 \mathrm{~mm}$, respectively (Zhou et al., 2000; Wang et al., 2001). As shown in Fig. 2a, the precipitation in the study region mainly falls in the three months from July to September, which accounts for $83 \%$ of the annual total precipitation. During the freezing season from November to April, the precipitation was less than $5 \mathrm{~mm}$. The distribution of 
Table 1. Physical and chemical characteristics of selected alpine meadow soils of the Qinghai-Tibet Plateau.

\begin{tabular}{|c|c|c|c|c|c|c|c|c|}
\hline \multicolumn{2}{|c|}{ Vegetation type } & \multicolumn{2}{|c|}{ Permafrost } & \multirow[t]{2}{*}{ Soil Profile (m) } & \multirow[t]{2}{*}{ Bulk density $\left(\mathrm{Mg} \mathrm{m}^{-3}\right)$} & \multicolumn{2}{|c|}{ Granularity } & \multirow[t]{2}{*}{ Organic matter $(\%)$} \\
\hline Type & Cover $(\%)$ & Depth (m) & Active layer (m) & & & $>0.5 \mathrm{~mm}(\%)$ & $<0.1 \mathrm{~mm}(\%)$ & \\
\hline \multirow{3}{*}{ Festuca sp., Poa spp. } & \multirow{3}{*}{30} & \multirow{3}{*}{$50-120$} & \multirow{3}{*}{$1.0-1.5$} & $0-0.10$ & 1.26 & 4.95 & 93.1 & 0.66 \\
\hline & & & & $0.10-0.20$ & 1.34 & 11.3 & 85.4 & 0.25 \\
\hline & & & & $0.20-0.40$ & 1.51 & 17.95 & 61.2 & 1.13 \\
\hline \multirow{3}{*}{ Kobresia humilis } & \multirow{3}{*}{65} & \multirow{3}{*}{$50-120$} & \multirow{3}{*}{$0.8-1.5$} & $0-0.10$ & 1.10 & 1.45 & 93.2 & 1.30 \\
\hline & & & & $0.10-0.20$ & 1.21 & 2.85 & 92.9 & 0.80 \\
\hline & & & & $0.20-0.40$ & 1.35 & 7.2 & 72.4 & 0.77 \\
\hline \multirow{3}{*}{ Kobresia humilis } & \multirow{3}{*}{93} & \multirow{3}{*}{$50-120$} & \multirow{3}{*}{$0.8-1.5$} & $0-0.10$ & 0.95 & 1.15 & 93.3 & 1.10 \\
\hline & & & & $0.10-0.20$ & 1.09 & 1.6 & 93.6 & 1.63 \\
\hline & & & & $0.20-0.40$ & 1.29 & 11.65 & 61.8 & 1.38 \\
\hline
\end{tabular}

yearly air temperature is consistent with the pattern of precipitation. The peak temperature occurs from July to August, and the monthly average air temperature remains consistently below $0^{\circ} \mathrm{C}$. Monthly mean surface soil temperatures $(5 \mathrm{~cm})$ show almost the same seasonal pattern as the one for air temperature in yearly average (Fig. 2a). The net radiation $(\mathrm{Rn})$ is positive year-round and its maximum is in June and July (Fig. 2b). Radiation was very high during summer compared with those of other places, such as arid regions, tropical grassland, temperate forests, Arctic tundra, and boreal forest regions (Eugster et al., 2000; Yao et al., 2007). This indicates that the solar radiation resource is abundant on the Tibetan Plateau in the summer. The lowest Rn is observed in the winter from December to February. The snow cover was irregular, filmy and discontinuously distributed over the ground surface, even in the middle of winter (Sato, 2001; Zhou et al., 2000). Therefore, the role of snow cover in the soil water-temperature coupling relationship and its changes under vegetative cover variance were not as those reported in other permafrost regions, such as those in North America and Siberia (Christensen et al., 2004), and was ignored in this study. Thus, the study aim can be focused on the impacts of the vegetation cover changes on soil water-temperature coupling relationship, and this is the another reason to select the area to this study.

\section{Methodology}

\subsection{Field observation}

Three observation locations for soil water-temperature coupling (A, B, and C) were selected within the Zuomao Kong watershed. The locations $\mathrm{A}$ and $\mathrm{C}$ represented grasslands of alpine meadows, and the location $\mathrm{B}$ represented alpine frost swamp grassland (Fig. 1). At location A, we selected three $20 \times 5 \mathrm{~m}$ (slope length $\times$ width) sampling plots with slopes of $18-21^{\circ}$, and their vegetation covers were 30,65 , and $93 \%$. Two soil-moisture observation points located one-third and two-thirds of the way down the slope of each plot housed a pair of $1.5 \mathrm{~m}$ deep wells used for measurements of soil water levels and temperature. In each well, soil moisture sensors and soil temperature $\left(T_{S}\right)$ sensors were installed at depths of $0.20,0.40,0.70,1.20$, and $1.50 \mathrm{~m}$. Before burying the water probes and temperature sensors, the soil bulk density at each point was determined using the cutting-ring method. A sample sieve was used to divide the soil granularity composition into a fraction of soil coarser than $2 \mathrm{~mm}$, and a fraction of soil finer than $2 \mathrm{~mm}$. The soil particle-size composition for the fraction of soil finer than $2 \mathrm{~mm}$ was determined using a CIS50 grain-size analyzer (Ankersmic Co., the Netherlands).

$\theta_{v}$ was the volumetric liquid water content of soil, which was determined by frequency domain reflectometry (FDR), using a calibrated soil moisture sensor equipped with a Theta-probe (Holland Eijkelamp Co.). $\theta_{v}$ was derived from changes in the soil's dielectric constant, converted to a millivolt signal. The accuracy of this procedure was $\pm 2 \%$.

$T_{S}$ was monitored using a thermal resistance sensor to measure temperature changes in the range of -40 to $50^{\circ} \mathrm{C}$, with an overall system precision of $\pm 0.02^{\circ} \mathrm{C}$. The thermal resistance sensors were developed by the State Key Laboratory of Frozen Soil Engineering (Lanzhou, China) using digital multimeters (Fluke 180 series, Fluke Co., USA). The sensors have been successfully used on the Qinghai-Tibet Plateau for the past 20 years (Wu et al., 2002, 2004).

Both $\theta_{v}$ and $T_{s}$ were monitored simultaneously at 2-h intervals from April to November, and at 6-h intervals from December to March for over 3 years (from 2004 to 2006). Two portable micro-meteorological stations were established in the experimental fields to measure the climatic factors of $T_{a}$ (at $1.2 \mathrm{~m}$ in height), precipitation, wind velocity and direction, and net radiation.

3.2 Analysis of changes in $\Theta_{V}-T_{S}$ coupling with vegetation cover

In permafrost region, the interactions between soil temperature and moisture not only control the water distribution 
Table 2. Soil heat content and its distribution in the soil profile of alpine meadow soils of the Qinghai-Tibet Plateau under different levels of vegetation cover.

\begin{tabular}{lcccccccc}
\hline \multirow{2}{*}{ Vegetation cover } & \multicolumn{3}{c}{ Soil freezing process kJ/m } & \multicolumn{4}{c}{ Soil thawing process kJ/m ${ }^{2}$} \\
& $20 \mathrm{~cm}$ & $40 \mathrm{~cm}$ & $70 \mathrm{~cm}$ & $120 \mathrm{~cm}$ & $20 \mathrm{~cm}$ & $40 \mathrm{~cm}$ & $70 \mathrm{~cm}$ & $120 \mathrm{~cm}$ \\
\hline 65 & -57.37 & -97.54 & -42.18 & -11.53 & 39.89 & 67.91 & 60.80 & 3.79 \\
93 & -26.05 & -91.78 & -34.23 & -11.06 & 29.60 & 50.80 & 56.95 & 2.60 \\
30 & -99.61 & -140.19 & -93.70 & -15.44 & 53.20 & 69.80 & 96.89 & 5.70 \\
\hline
\end{tabular}

and dynamic change in active layer, but also impact on the land surface processes. However, the dynamic interactions between $\theta_{v}-T_{s}$ relationships and vegetation remain largely unresolved because the lack of mechanism based analysis method. At present, the rational method based on statistical analysis, most widely used for analyzing soil $\theta_{v}-T_{s}$ relationship based on field observational data (Jansson and Karlberg, 2001; Kang et al., 2004), We analyzed the $\theta_{v}-T_{s}$ relationship and changes in the relationship using two different approaches: (i) using a regression model and (ii) by analyzing the distribution of and variation in coupled soil water-heat regimes.

Using statistical methods available in SAS 8.1 (SAS Institute 2000), we generated a regression model linking $\theta_{v}$ and $T_{S}$ from mean daily data collected at different soil depths and under different vegetation covers. Models developed for different levels of vegetation cover served to analyze the effects of changes in vegetation cover on the coupling of $\theta_{v}$ and heat.

The effectiveness of the model was evaluated using two terms: the Nash and Sutcliffe (1970) coefficient of efficiency of the match between the simulated and observed daily soil $\theta_{v}-T_{s}$, and the relative error (RE) of soil $\theta_{v}-T_{S}$. The NashSutcliffe coefficient of efficiency, NSE (Nash and Sutcliff, 1970), is a dimensionless indicator widely used to evaluate hydrological models. NSE is better suited to evaluate model goodness-of-fit than the coefficient of determination, $\mathrm{R}^{2}$ (Legates and McCabe, 1999). RE was used to determine the fitting error of the soil $\theta_{v}-T_{s}$ curve to observed values. $N S E$ and $R E$ are calculated as:

$$
\begin{aligned}
& N S E=1.0-\left(\sum_{i=1}^{N}\left(O_{i}-P_{i}\right)^{2} / \sum_{i=1}^{N}\left(O_{i}-\overline{O_{i}}\right)^{2}\right) \\
& R E=\frac{\left(O_{i}-P_{i}\right)}{O_{i}} \times 100 \%
\end{aligned}
$$

where: $\mathrm{O}_{i}=$ measured (observed) data, $\mathrm{P}_{i}=$ modeled (predicted) data, $\bar{O}=$ mean of measured data.

We selected soil temperature parameters closely related to $\theta_{v}$, such as soil freezing temperature $\left({ }^{f} T_{S}\right)$, soil thawing temperature $\left({ }^{t} T_{s}\right)$, soil-air temperature difference $\left(\Delta T_{a-s}=T_{a^{-}}\right.$$T_{S}$ ), and soil heat content, to analyze the effects of changes in vegetation cover on coupled soil water-heat regimes. The parameters ${ }^{t} T_{s}$ and ${ }^{f} T_{s}$ were determined using the inflexion point method, based on plots of $\theta_{v}$ vs $T_{s}$. In order to lower the value of $T_{S}$, we took ${ }^{f} T_{s}$ to be the point where $\theta_{v}$ dropped sharply to a lower and relatively stable value. At this point, the simplifying assumption is that all water is frozen except for a small residual quantity. Conversely, as $T_{s}$ increased in a frozen soil, we took ${ }^{t} T_{s}$ to be the point at which the water content showed a sharp increase to a higher and relatively stable value.

When $T_{s}>0^{\circ} \mathrm{C}$, the $\theta_{v}$ calculated from FDR data reflected the volumetric soil liquid-water content. When $T_{s}<0^{\circ} \mathrm{C}$, the soil water content equalled the volumetric soil liquid plus ice content, which was assumed to be the same as the liquid water content that observed preceding the fall before the soil started freeze, permitting that there was no significant change in the FDR data when the soil was actually frozen. Barring significant shifts in the FDR data, the difference in FDR data between the values of $\theta_{v}$ taken at the time immediately before the soil froze and the stable values of $\theta_{v}$ taken at the time of soil frozen were taken as the volumetric soil solid-water content (Zhou et al., 2000; Zhang et al., 2003). However, it is impossible to ascertain the accuracy of the ice content due to a lack of technology; the ice content is known to change over time because the temperature gradient leads liquid water toward the freezing front (Cheng, 1984).

When $T_{s} \approx{ }^{f} T_{s}$, and when all but a small residual quantity of water is assumed to be in solid form, the soil heat content, $E_{f}$, is a function of the latent heat and sensible heat (Jansson and Karlberg, 2001; Kang et al., 2005):

$E_{f}={ }^{f} C_{s}^{f} T_{s}-L_{f} W_{i c}$

where, $L_{f}$ is the latent heat of freezing, approximately $334 \mathrm{~kJ} \mathrm{~kg}^{-1}$ (Chen et al., 2006), $W_{i c}$ is the potential freezing water content, and ${ }^{f} C_{s}$ is the soil heat capacity of frozen soil $\left(\mathrm{kJ} \mathrm{m}^{-3 \circ} \mathrm{C}^{-1}\right)$, as given by (Jansson and Karlberg, 2001; Chen et al., 2006)

${ }^{f} C_{s}=f_{s} C_{s}+{ }^{i} \theta_{s} C_{i}+{ }^{r} \theta_{s} C_{w}$

where, $C_{s}$ is the heat capacity of the solid soil matrix, $C_{i}$ and $C_{w}$ are the heat capacities of ice and liquid water, respectively, ${ }^{i} \theta_{s}$ and ${ }^{r} \theta_{s}$ are the soil ice-water content and soil residual liquid-water content, respectively, and $f_{s}$ is the volumetric content of the solid soil matrix. 

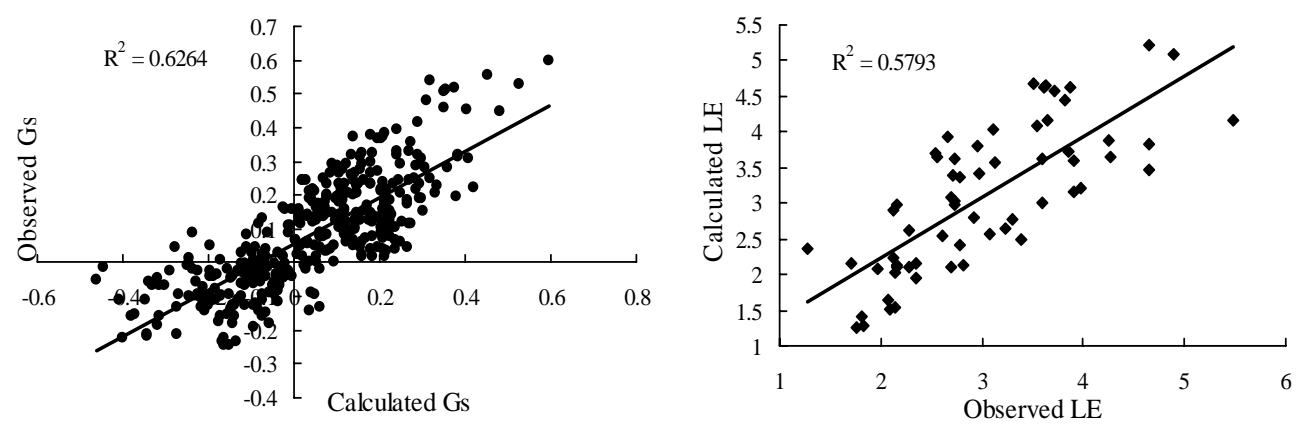

Fig. 3. The comparison of calculated Gs with observed Gs (a), and calculated LE with the observed LE (b).

During the initial freezing or thawing process, the soil is in a partly-frozen state; therefore, the soil heat value, $E_{t}$, can be approximated as follows (Jansson and Karlberg, 2001; Chen et al., 2006):

$E_{t}=L_{f} w\left(\frac{T_{s}}{T_{f}}\right)^{\frac{\lambda d_{3}+d_{2}}{d_{2} d_{3}}}+C_{i} T_{s}$

where, $w$ is the total soil water content, $d_{2}$ and $d_{3}$ are empirical constants, and $\lambda$ is the soil particle-size distribution index.

3.3 Determination of soil surface heat flux, including nearsurface heat budget

The surface energy balance equation can be expressed as follows (Mayocchi and Bristowa, 1995):

$R n-G s-L E-H=0$

Net radiation $R n$, is measured with net radiometers, whereas the sensible heat flux $\left(H, \mathrm{Wm}^{-2}\right)$ and the latent heat flux $\left(L E, \mathrm{~W} \mathrm{~m}^{-2}\right)$ were calculated by using SHAW model due to lack of observation (NWRC, 2004; Flerchinger, 2000). The soil surface heat fluxes $G s$, a measure of the energy that enters (or leaves) the soil, then can be calculated by the Eq. (4).

To investigate the validity of the created SHAW model in the study region, the data of GAME/Tibet Amdo site were used to compare with the modelling results (Zhang et al., 2003). Figure 3 shows the statistical results of the calculated $L E$ and $G s$ with the observed data. The results from calculation are similar to observation. The coincidence between their variation trends was statically significant with coefficient $R$ over 0.794 and $P<0.01$, indicating that the created SHAW model was valid and appropriate in the study region.

\subsection{Soil laboratory analysis}

All soil samples were analyzed for soil particle size, organic matter content and bulk density by recommended methods (Ministry of Agriculture of China, 1993). The soil granularity and the soil bulk density were analyzed using CIS-50 grain-size analyzer (Ankersmic Co., Netherlands). Soil organic matter was determined using Walkley-Black method. All determinations were replicated twice, from which a mean value was calculated for each site.

\section{Results}

4.1 Energy fluxes regime and its seasonal change with degree of vegetation coverage

$H$ increased with the increase of $R n$ from February, but started to decrease from late June, even when $R n$ continued to increase, reaching a lower volume in July-August when the foliage attained its maximum coverage (Fig. 4). $H$ then began to increase again, with a second peak appearing around October. $L E$ started to increase in late March, and the maximum value appeared in late July because the high vegetation coverage, and soil water further increased $L E$ during the growth period. When the soil was frozen in October, the $L E$ became extremely small, generally smaller than $H$ during the winter season (from November to February). Gs varied between 23.15 and $-23.15 \mathrm{Wm}^{-2}$, and reached a maximum value around June-July, and then dropped below zero in early October (Fig. 4).

Vegetation cover variation had a significant influence on the energy flux regime. As vegetation cover increased, the $H$ and $G s$ decreased (Fig. 4a and c). The annual and winter season average $H$ values under the $30 \%$ cover exceeded those under $93 \%$ cover by $16 \%$ and $19 \%$, respectively. Under the $30 \%$ cover, the $G s$ that travelled downward to deep soil from the surface during the warm season between June and September was $23.2 \%$ and $41.2 \%$ more than those of $65 \%$ and $93 \%$ cover, respectively. In the winter season between October and February, however, the Gs overflowed upward from soil toward the air exceeded those of $65 \%$ and $93 \%$ cover by $17.3 \%$ and $38.1 \%$, respectively (Fig. 4c). This implies that the smaller the vegetation cover, the more likely that the energy will be consumed to increase soil temperature, and therefore have more soil surface heat flux. 
Table 3. Regression models of the relationship between the soil moisture content $\left(\theta_{v}\right)$ and soil temperature $\left(T_{S}\right)$ of alpine meadow soils of the Qinghai-Tibet Plateau under different levels of cover and during the freezing and thawing processes.

\begin{tabular}{llllll}
\hline Period & $\begin{array}{l}\text { Vegetation } \\
\text { cover }(\%)\end{array}$ & $\begin{array}{l}\text { Models relating } \\
T_{S} \text { and } \theta_{v}\end{array}$ & $\begin{array}{l}\text { Correlation } \\
\text { coefficient } R\end{array}$ & $\begin{array}{l}\text { Relative } \\
\text { error }(\%)\end{array}$ & $\begin{array}{l}\text { Standard } \\
\text { error }(\%)\end{array}$ \\
\hline \multirow{4}{*}{ Frozen } & 93 & $T_{s}=-9.24+9.0 /\left(1+\exp \left[-\left(\theta_{v}-13.05\right) / 0.74\right]\right.$ & 0.97 & 0.15 & 0.45 \\
& 65 & $T_{S}=-275.3+274.9 /\left(1+\exp \left[-\left(\theta_{v}+0.48\right) / 1.47\right]\right.$ & 0.98 & 0.30 & 0.51 \\
& 30 & $T_{S}=-78.2+78.1 /\left(1+\exp \left[-\left(\theta_{v}-2.93\right) / 1.51\right]\right.$ & 0.94 & 0.43 & 0.58 \\
\multirow{3}{*}{ Thaw } & 93 & $T_{S}=^{-} 1.16+\left(0.46 \times \ln \left|\left(\theta_{v}-13.86\right)\right|\right)$ & 0.91 & 2.5 & 0.38 \\
& 65 & $T_{S}={ }^{-} 0.96+\left(0.50 \times \ln \left|\left(\theta_{v}-5.94\right)\right|\right)$ & 0.88 & 6.1 & 0.41 \\
& 30 & $T_{S}=-1.02 \times \theta_{v} /\left(-4.15+\theta_{v}\right)+0.115 \times \theta_{v}$ & 0.93 & 0.5 & 0.43 \\
\hline
\end{tabular}

Note: $T_{S}$, soil temperature; $\theta_{v}$, volumetric soil moisture.

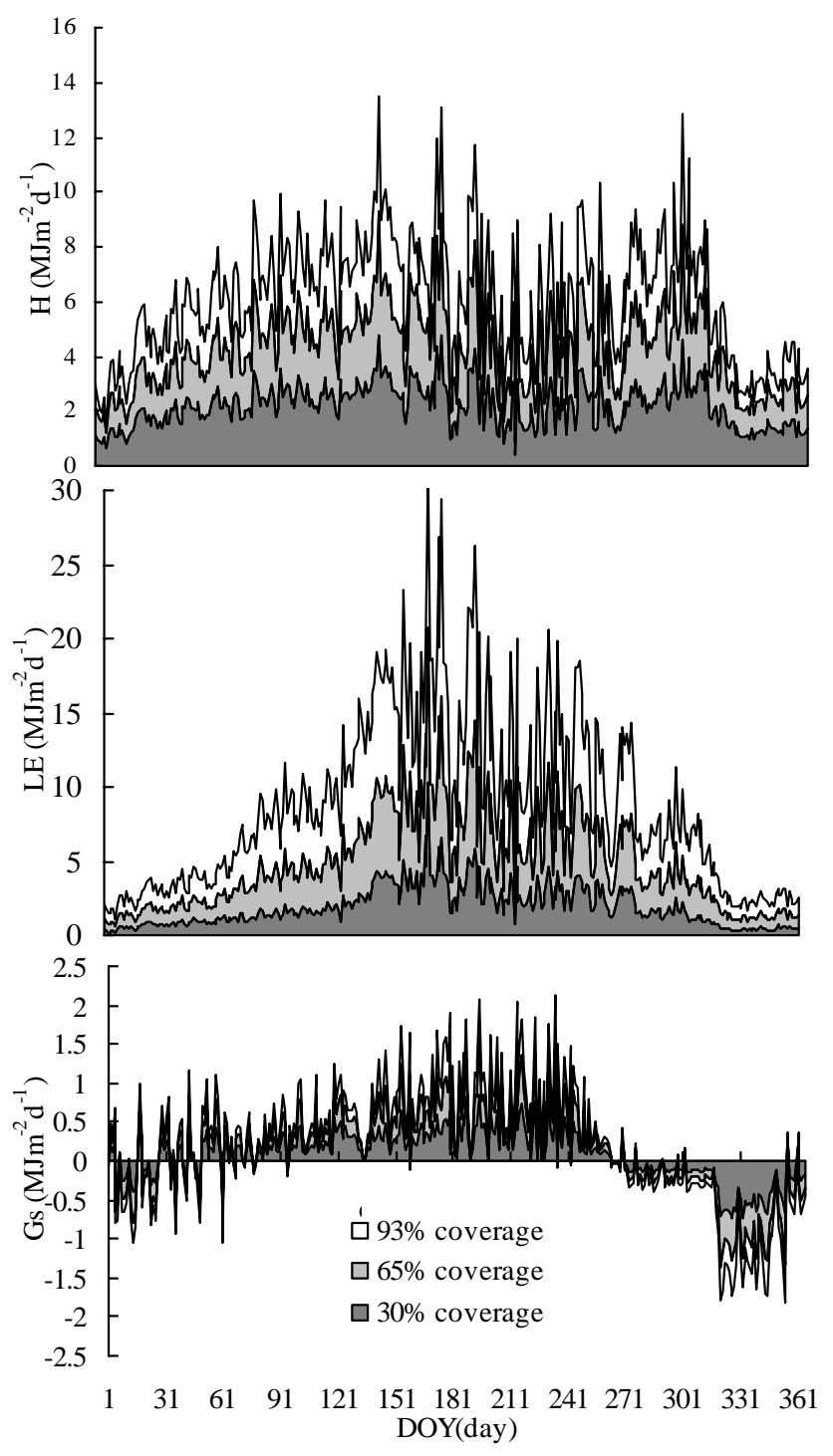

Fig. 4. Seasonal variations of daily-integrated sensible heat flux $(\mathrm{H})$, latent heat flux (LE), and soil heat flux (Gs).
During the frozen-soil period, LE was very low with a mean value of $6.94 \mathrm{Wm}^{-2}, 12.73 \mathrm{Wm}^{-2}$ and $16.2 \mathrm{Wm}^{-2}$ for $30 \%, 65 \%$ and $93 \%$ covers, respectively (Fig. 4b). Most energy was converted to $H$, with a mean of $18.52 \mathrm{Wm}^{-2}$, $16.2 \mathrm{Wm}^{-2}$ and $13.89 \mathrm{Wm}^{-2}$ for $30 \%, 65 \%$ and $93 \%$ covers, respectively. In thawing-soil period, LE rapidly increased due to the increases in precipitation and vegetation cover, and gradually became the dominant component during June and July. However, $H$ increased again after September as $L E$ and $G$ rapidly decreased. During the summer season (from June to August), the mean LE values were $35.88 \mathrm{Wm}^{-2}$, $50.92 \mathrm{Wm}^{-2}$ and $68.28 \mathrm{Wm}^{-2}$, with 1.4 fold, 2.1 fold and 3.1 fold of the mean $H$ value for $30 \%, 65 \%$ and $93 \%$ covers, respectively (Fig. 4b).

The soil heat content, represented by $E_{f}$ or $E_{t}$ (Eqs. 1 and 3 ) and its distribution throughout the soil profile were assessed under different vegetation covers during the freezing and thawing processes (Table 2). During the freezing process, the greater the value of $\theta_{v}$ at freezing, and the smaller the vegetation cover, the greater the resulting $E_{f}$ (Fig. 5 and Table 2). Given that the gradient in $T_{S}$ with depth rose to increased accumulation of soil water in the upper active layer, the value of $\theta_{v}$ in the upper $0.20-0.40 \mathrm{~m}$ soil layer was greater than that in the deeper layer, leading to a significantly higher value of $E_{f}$ in the shallow layer. Therefore, the distribution of soil $E_{f}$ and shifts in these values were the result of the combined effects of vegetation cover and initial $\theta_{v}$. During the April-June thawing of the active layer, $E_{f}$ was dominated by downward transmission. At any given depth within the active layer, $E_{f}$ decreased with increasing vegetation cover; $E_{f}$ under $93 \%$ cover was $6.4-78.0$ and 27.2$85.5 \%$ lower than that under 65 and $30 \%$ covers, respectively.

4.2 Coupling of $\Theta_{V}$ and $T_{S}$ and its variation with the degree of vegetation coverage

4.2.1 The variation of the $\theta_{v}-T_{s}$ coupling relationship with the degree of vegetation coverage

In permafrost region, the close interaction between active soil water and heat is the main factor to control the water cycle 

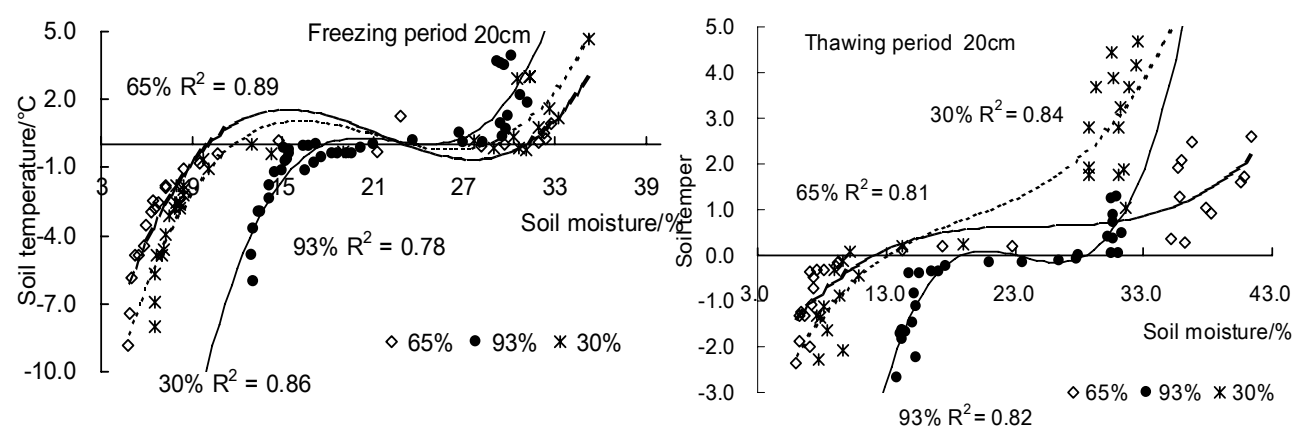

Fig. 5. Relationship between soil moisture content $\left(\theta_{v}\right)$ and soil temperature $\left(T_{S}\right)$ for alpine meadow soils of the Qinghai-Tibet Plateau. Data are plotted for different levels of vegetation cover during the freezing and thawing processes at $20 \mathrm{~cm}$ in depth.
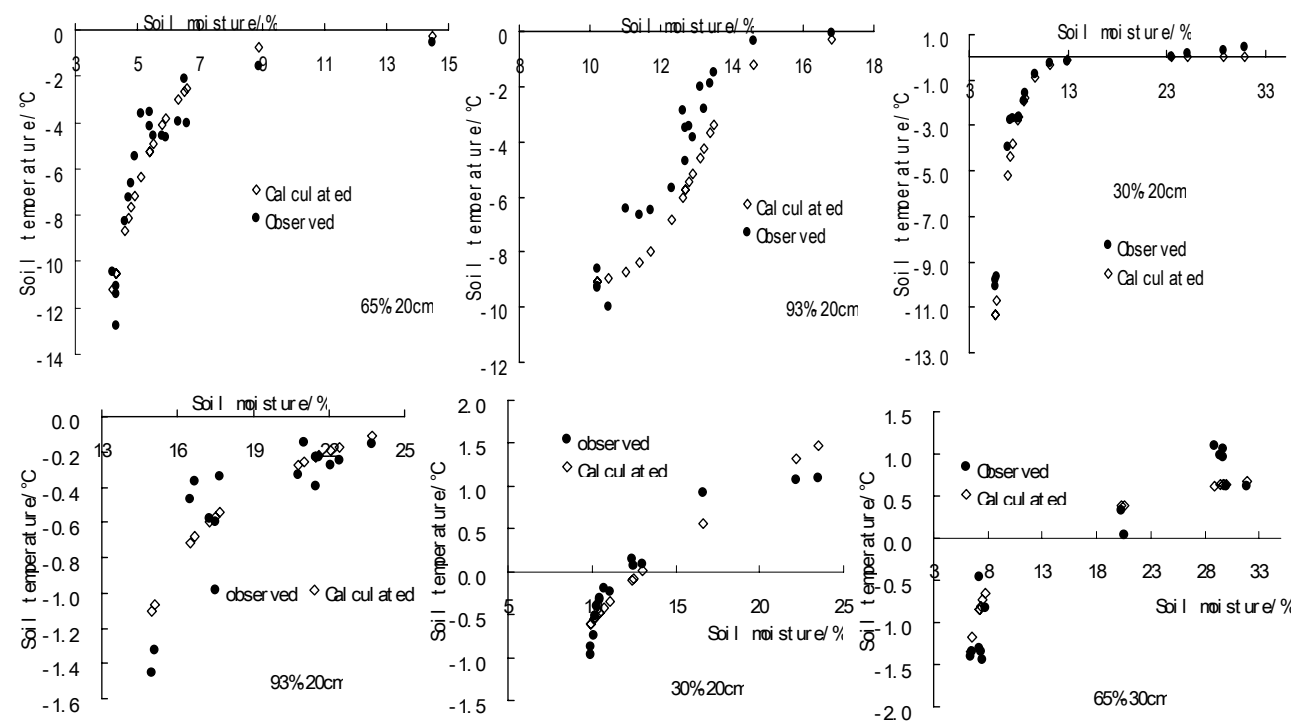

Fig. 6. Comparison of $\theta_{v}-T_{S}$ coupling based on predicted and observed $T_{S}$ during freezing processes (a) and thawing processes (b).

and surface energy balance. In order to reveal the impacts of vegetation cover changes on the soil water and temperature coupling relationship, the upper $0.2 \mathrm{~m}$ layer is selected to analyze the response of $\theta_{v}-T_{s}$ relationship to vegetation cover changes. Using observation data from the upper-slope point, we plotted the $\theta_{v}-T_{s}$ relationship for the soil freezing (Fig. 5a) and thawing (Fig. 5b) processes in the upper $0.2 \mathrm{~m}$ layer of alpine meadow soils under different levels of vegetation cover. For soil temperatures between entirely frozen soil $\left({ }^{f} T_{s}\right)$ and $5^{\circ} \mathrm{C}, \theta_{v}$ and $T_{s}$ exhibited a strong correlation, regardless of the level of vegetation cover.

Based on Fig. 5, regression analysis was used to develop coupled $\theta_{v}-T_{s}$ models for periods of freezing and thawing under different levels of vegetation cover (Table 3 ). During the freezing process, $\theta_{v}$ and $T_{s}$ showed an S-shaped relationship under different levels of vegetation cover $(R>0.94, P<$ 0.001 , fitting $\mathrm{RE}<0.45 \%$ ). During the thawing process, the patterns of regression models between $\theta_{v}$ and $T_{s}$ were dis- tinct from those of freezing process, under all levels of vegetation cover. Nonetheless, these $\theta_{v}-T_{s}$ relationships showed a strong correlation $(R>0.88, P<0.001$, fitting $\mathrm{RE}=2.5-$ $6.1 \%)$.

The regression models (Table 3) were used to simulate $T_{s}$ for both the freezing (Fig. 6a) and thawing (Fig. 6b) periods under different levels of vegetation cover using the observed values of $\theta_{v}$, The simulation accuracy for the coupled $\theta_{v}-E_{f}$ was greater under low vegetation cover than under high vegetation cover. The simulation relative error RE and NSE are presented in Table 4. For the freezing process, the NSE values for the coupled $\theta_{v}-T_{S}$ model run under vegetation covers of 30,65 , and $93 \%$ were $90.3,86.4$, and $61.3 \%$, respectively, and the relative simulation error was in the range of 13.5 to $21 \%$. For the thawing process, the NSE for the coupled $\theta_{v^{-}}$ $T_{S}$ model exceeded $75 \%$, and the relative error was in the range of 2.1 to $20 \%$, better than that of the model for freezing process, in which the efficiency coefficient decreased with 

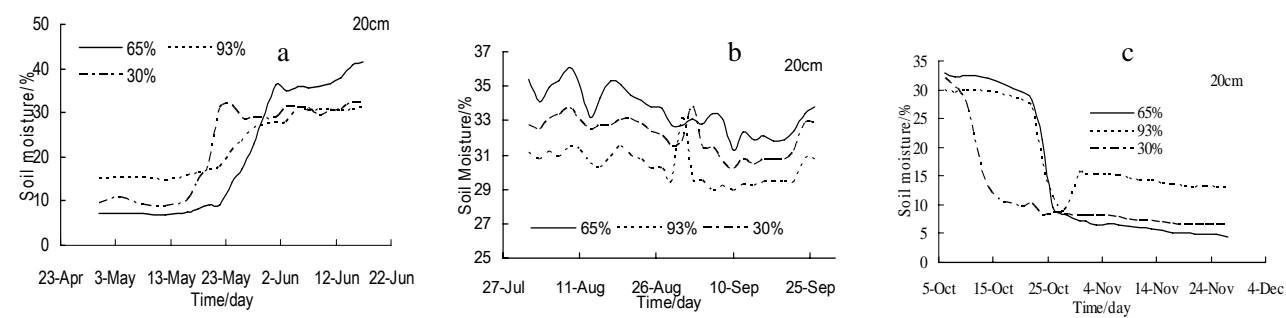

Fig. 7. Soil water content and distribution within the upper active soil layer under different vegetation cover during the (a) thawing process, (b) entirely thawed state and (c) freezing process.

Table 4. Accuracy of the simulated soil heat content of alpine meadow soils of the Qinghai-Tibet Plateau under different levels of vegetation cover.

\begin{tabular}{lllllll}
\hline & \multicolumn{5}{c}{ Percent cover } \\
Period & \multicolumn{2}{c}{$93 \%$} & \multicolumn{2}{c}{$65 \%$} & \multicolumn{2}{c}{$30 \%$} \\
& RE & NSE & RE & NSE & RE & NSE \\
\hline Freezing & 21.4 & 61.3 & 13.5 & 86.4 & 19.1 & 90.3 \\
Thawing & 2.1 & 75.3 & 20.0 & 83.5 & 12.5 & 87.1 \\
\hline
\end{tabular}

Note: RE, relative error; NSE, Nash-Sutcliffe coefficient of efficiency.

increasing vegetation cover. The effects of vegetation cover on the coupled $\theta_{v}-T_{S}$ relationship are mainly manifest in the following two factors.

(i) Soil freezing process: For a given $T_{s}, \theta_{v}$ increased with increasing vegetation cover (Fig. 6a). The general regression model for $\theta_{v}-T_{S}$ coupling during the freezing process can be given as

$T_{s}=S T_{c}+A_{c} /\left[1+\exp \left(\theta_{0}-\theta_{v}\right) / B_{c}\right]$

where, $S T_{c}$ and $A_{c}$ are $T_{s}$-related coefficients applicable when the soil is entirely frozen and $\theta_{v}$ remains stable, $\theta_{0}$ is a moisture-adjustment coefficient related to the initial freezing of soil water, and $B_{c}$ is the vegetation cover adjustment coefficient, inversely related to the extent of vegetation cover Both $S T_{c}$ and $\theta_{0}$ are indirectly affected by changes in vegetation cover.

The essence of such a relationship lies in the fact that the different soil moisture contents under contrasting vegetation covers resulted in different soil heat capacities and heat consumption for transformations of the water phase. For any given gradient in soil moisture, the change in soil temperature was smaller under grassland with a high vegetation cover (over 65\%) than that under low vegetation cover (below $30 \%$ ). There is a consistency to the phenomenon during the freezing process (Fig. 6); the liquid water moved towards the freezing front and formed relatively high liquid water content at the soil freezing temperature caused by temperature gradient under different vegetation covers. (ii) Soil thawing process: For soil under a vegetation cover of $93 \%$, the liquid water content in the $0-20 \mathrm{~cm}$ soil layer reached a maximum value at a soil temperature of $0.2^{\circ} \mathrm{C}$. Under vegetation covers of 65 and $30 \%$, it attained maximum values at 1 and $1.5-2.0^{\circ} \mathrm{C}$, respectively (Fig. 5 and $6 \mathrm{~b}$ ). This implies that the lower the vegetation cover, the more sensitive heat is consumed to increase the soil temperature. Furthermore, the more the vegetation cover, the more latent heat is consumed to transfer ice to liquid water and increase soil liquid water content.

In contrast to the freezing process, the pattern of $\theta_{v}$ $T_{s}$ coupling during the thawing process showed some variation with different degrees of vegetation cover (Table 3 and Fig. 6b). For non-degraded or slightly degraded alpine meadow soils, a three-parameter logarithmic curve relationship provided the best fit to the data, whereas for severely degraded vegetation cover, a single-axis hyperbolic regression model that provided a better fit for the significance of this relationship. The main causes for different $\theta_{v}-T_{s}$ coupling pattern were possibly the variation of energy balance and the initial ice content in the $0-20 \mathrm{~cm}$ soil layer under different vegetation covers. During the thawing processes, the heat flux entered into soil, and its transferring rate increased with vegetation cover decrease. Therefore, the latent heat consumption increased more quickly with the increase of vegetation cover. The different energy balance and soil water (ice) content were also the reason of the variation in simulation accuracy with different degrees of vegetation cover.

Based on extensive experimental data obtained from the State Key Laboratory of Frozen Soil Engineering (Lanzhou, China), but without taking into account the influence of vegetation cover, Xu et al. (2001) derived an empirical formula for $\theta_{v}-T_{s}$ coupling relationship in describing frozen soils: $\theta=a|T-273.15|^{-c}$. The basic structure of this formula is similar to that for the $\theta_{v}-T_{s}$ coupling relationship of the soil thawing process under a higher vegetation cover (see Table 3). 

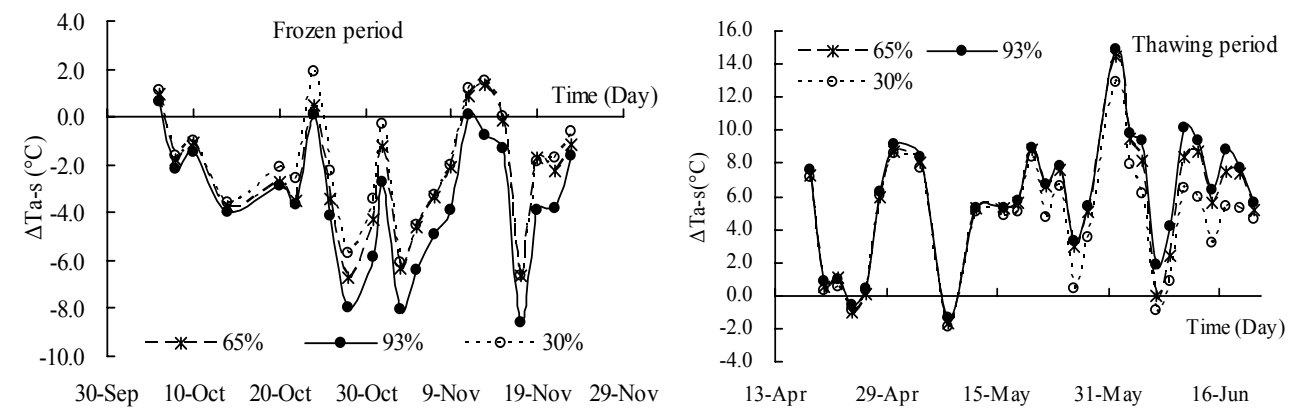

Fig. 8. Relationship between the soil-air temperature difference $\left(\Delta T_{a-s}\right)$ and air temperature $\left(T_{a}\right)$ at $20 \mathrm{~cm}$ in depth during the freezing and thawing processes for the studied alpine meadow soils under different levels of vegetation cover.

\subsubsection{Effects of changes in vegetation cover on the soil wa- ter content}

Due to the variations of $\theta_{v}-T_{s}$ coupling relationship, active soil $\theta_{v}$ and its distribution through the profile changed significantly under different levels of vegetative cover (Fig. 7). During thawing process, the soil water thaw-rise time of the $0-0.20 \mathrm{~m}$ soil layer occurred 6-7 days earlier under $30 \%$ cover than under $65 \%$ cover, and 5-6 days earlier than under $93 \%$ cover (Fig. 7a). Under $93 \%$ cover, the relative amplitude of thaw-rise in $\theta_{v}$ is 1.5 - to 40.5 -fold lower than under $30 \%$ cover. Thus, the greater the vegetative cover, the later the soil water thaw-rise started and the lesser the amplitude of soil water content rise (Fig. 7a). During August and September, when the study area's $1.80 \mathrm{~m}$ deep active layer was entirely in a thawed state, the water content in topsoil layer under $93 \%$ cover is $6.1 \%-10.5 \%$ lower than under $30 \%$ cover (Fig. 7b).

During the freezing process, the water content in $0-0.20 \mathrm{~m}$ soil layer under $30 \%$ cover began its freeze-drop with 14 days earlier than under $65 \%$ and $93 \%$ vegetative, respectively. The greater the cover, the later the soil water content drop for the active layer of the soil profile (Fig. 7c). The freeze-fall amplitude of soil water is similar to that for the thawing process. For a given soil depth, the greater the vegetative cover, the lesser the freeze-fall amplitude of soil water. When active layer was entirely in a frozen state, the no-frozen liquid $\theta_{v}$ determined by FDR was low $(1.3-15 \%)$, the greatest $\theta_{v}$ occurred in the profile under $93 \%$ cover (Fig. 7c). Thus, it can be concluded that as vegetative cover decreased, soil water circulation in the active layer increased, and the response to temperature of the water distribution across the soil profile was heightened.
4.3 Effects of vegetation cover on the soil water-heat coupling regime

\subsubsection{Effects of changes in vegetation cover on the soil-air temperature difference}

Land-atmosphere energy exchange upon alpine meadows has an important influence on the soil water cycle. Given that surface vegetation is an intermediate step in land-atmosphere energy transmission process, it is important to understand how changes in vegetation cover pattern affect this process in permafrost regions.

Figure 7 shows the dynamic changes in soil-air temperature difference under different levels of vegetation cover This result was obtained from the analysis of observed soil temperatures in the top $20 \mathrm{~cm}$ layer of soil and surface air temperatures. During the thawing process, $\Delta T_{a-s}$ was positive, indicating that heat was transmitted from the atmosphere to the soil. During the freezing process, the mean daily soil temperature was higher than the air temperature, or negative $\Delta T_{a-s}$, indicating that heat was transmitted from the soil to the atmosphere. During the initial freezing process (from 30 September to 20 October) and the initial thawing process (from 15 April to 20 May), $\Delta T_{a-s}$ was small and largely invariant under different levels of vegetation cover. When the top 0-20 cm layer soil was either entirely thawed or entirely frozen, $\Delta T_{a-s}$ had a tendency to increase with increasing vegetation cover.

The $\Delta T_{a-s}-T_{s}$ plots for the soil thawing process showed significantly steeper slopes than those for the freezing process (Table 5). The slopes of $\Delta T_{a-s}-T_{s}$ plots for $93 \%$ vegetation exceeded those for 65 and $30 \%$ cover by 3.5 and $17.4 \%$, respectively. Similarly, the mean $\Delta T_{a-s}$ values obtained under $93 \%$ vegetation cover exceeded those under 65 and $30 \%$ cover by 8.3 and $26.7 \%$, respectively. The $\Delta T_{a-s}-H$ plots show a significantly liner relationship exist only for $-1^{\circ} \mathrm{C}<\Delta T_{a-s}<1^{\circ} \mathrm{C}$ (Fig. 8), and that the relationship of $\Delta T_{a-s}-H$ is more slight when $\Delta T_{a-s}<-1{ }^{\circ} \mathrm{C}$ and $1^{\circ} \mathrm{C}<\Delta T_{a-s}$. The soil water phase transmutation is one of the main driving forces that cause the variation of the 
Table 5. Comparison of the mean soil-air temperature difference $(\Delta \bar{T} \mathrm{a}-\mathrm{s})$, soil freezing temperature $\left({ }^{f} T_{S}\right)$, and soil thawing temperature ${ }^{t} T_{S}$ ) of alpine meadow soils of the Qinghai-Tibet Plateau under different levels of vegetation cover.

\begin{tabular}{llllllllll}
\hline \multirow{2}{*}{ Vegetative Cover } & \multicolumn{3}{c}{ Freezing process } & \multicolumn{3}{c}{ Thawing process } & \multicolumn{2}{c}{ Warm season } \\
& Slope & $\Delta \bar{T} \mathrm{a}-\mathrm{s}$ & $f_{S}$ & Slope & $\Delta \bar{T} \mathrm{a}-\mathrm{s}$ & ${ }^{t} T_{s}$ & Slope & $\Delta \bar{T} \mathrm{a}-\mathrm{s}$ \\
\hline 93 & 0.66 & -3.5 & -0.10 & 0.86 & 6.0 & 0.04 & 1.02 & 4.5 \\
65 & 0.55 & -2.4 & -0.78 & 0.83 & 5.5 & 0.3 & 0.95 & 4.2 \\
30 & 0.52 & -2.0 & -1.77 & 0.71 & 4.4 & 1.74 & 0.86 & 3.5 \\
\hline
\end{tabular}

$\Delta T_{a-s}-H$ relationship. Fig. 8 shows that the $\Delta T_{a-s}-H$ relationship is more significant under $93 \%$ vegetation cover than that under $30 \%$ vegetation cover, implying that more heat devote to $\mathrm{H}$ in active soil under $30 \%$ vegetation fraction.

During the warm season (from 20 July to 10 September) when the active layer soil was entirely thawed, vegetation within the alpine meadow showed rapid growth, and a significant linear relationship was observed between $\Delta T_{a-s}$ and $T_{a}$, with the values of former extending over a greater range than that recorded during the freezing or thawing processes (Table 5). As the freezing and thawing processes progress, the slopes of $\Delta T_{a-s}-T_{s}$ plots for the warm season increase with increasing vegetation cover. The $\Delta T_{a-s}-T_{s}$ slope for soil under $93 \%$ vegetation cover exceeded those for 65 and $30 \%$ cover by 6.9 and $15.7 \%$, respectively. Similarly, the mean $\Delta T_{a-s}$ values obtained under $93 \%$ cover exceeded those under 65 and $30 \%$ cover by 6.7 and $22.2 \%$, respectively.

4.3.2 Effects of vegetation cover on the freezing and thawing temperature of the active layer

Soil freezing and thawing temperatures are related to factors such as vegetation cover, soil moisture, soil salt content, and soil structure. Given that the observation points in this study were all located within the same geomorphological unit and soil type, the soil salt contents and fine-grained composition of the soil of the different points are essentially the same (Table 1). Therefore, the effect of soil salt content on the soil water-heat regime is not relevant in this study. The data in Table 5 show that the soil freezing temperature fell with decreasing vegetation cover.

Values of ${ }^{t} T_{S}$ and ${ }^{f} T_{S}$ show a close relationship to $\theta_{v}$ (Oechel et al., 2000; Zhou et al., 2000), and vary with vegetation cover (Table 5). ${ }^{f} T_{S}$ decreased with decreasing vegetation cover; under a cover of $93 \%$, soil within the alpine meadow began to freeze at about $-0.1^{\circ} \mathrm{C}$, whereas under moderately degraded grassland $(63 \%$ cover $)$ it began to freeze at between -0.7 and $-0.8^{\circ} \mathrm{C}$. For severely degraded alpine meadow ( $30 \%$ cover), values of ${ }^{f} T_{s}$ were 1.6 and $1.0^{\circ} \mathrm{C}$ lower than those under 63 and $93 \%$ cover, respectively.

${ }^{t} T_{s}$ increased with decreasing vegetation cover. Highcover alpine meadow soil thawed entirely at approximately $0.04^{\circ} \mathrm{C}$, whereas moderate-cover soil thawed entirely at
Table 6. Variation in thaw/frozen depth under different vegetation cover fraction.

\begin{tabular}{llllllll}
\hline \multirow{2}{*}{ Time } & \multicolumn{3}{c}{ Freezing depth $(\mathrm{cm})$} & \multirow{4}{*}{ Time } & $30 \%$ & $65 \%$ & $93 \%$ \\
& $30 \%$ & $65 \%$ & $93 \%$ & & & & \\
& & & & & & & \\
15 Oct & 32 & 20 & 0 & 30 May & 52 & 18 & 11 \\
30 Oct & 110 & 64 & 43 & 15 Jun & 105 & 47 & 35 \\
15 Nov & 160 & 140 & 140 & 30 Jun & 130 & 64 & 56 \\
\hline
\end{tabular}

Note: $30 \%, 65 \%$ and $93 \%$ represent the vegetation cover fraction of $30 \%, 65 \%$ and $93 \%$, respectively.

$0.3^{\circ} \mathrm{C} .{ }^{t} T_{s}$ with highly-degraded (30\% cover) alpine cold meadow was 1.7 and $1.3^{\circ} \mathrm{C}$ higher than that for high-cover $(93 \%)$ or moderate-cover $(63 \%)$ soils, respectively.

Prior to mid-July, soil temperature showed marked variations under different levels of vegetation cover (Fig. 9a); mean soil temperature in the $0-20 \mathrm{~cm}$ layer under $30 \%$ cover was $2.5^{\circ} \mathrm{C}$ higher than that under $93 \%$ cover and $1.3^{\circ} \mathrm{C}$ higher than that under $65 \%$ cover. After mid-July, soil in the $0-20 \mathrm{~cm}$ layer thawed entirely, leading to a reduction in the magnitude of variation in soil temperature under different levels of vegetation cover. However, the soil temperature under $30 \%$ cover was still higher than that under more extensive covers, and we found that the higher the vegetation cover, the lower the soil temperature. During the freezing process (Fig. 9b), greater vegetation cover was associated with smaller amplitudes of soil temperature change and higher soil temperature.

The variation of ${ }^{t} T_{S}$ and ${ }^{f} T_{S}$ inevitably affected the thaw/frozen depth. Table 6 shows that the depth of thaw/frozen differed greatly under different vegetation cover. By 15 October, the frozen depth reached to $30 \mathrm{~cm}$ under $30 \%$ vegetation cover, but no frozen soil was observed in the topsoil layer under $93 \%$ vegetation cover. Not until late October did the difference of frozen depth between $30 \%$ and $93 \%$ vegetation cover fraction reach $67 \mathrm{~cm}$ or more. For the thawing processes, the thawed soil depth under $30 \%$ vegetation cover was $41 \mathrm{~cm}$ greater than that under $93 \%$ vegetation cover in late May, with the difference reaching $74 \mathrm{~cm}$ by 

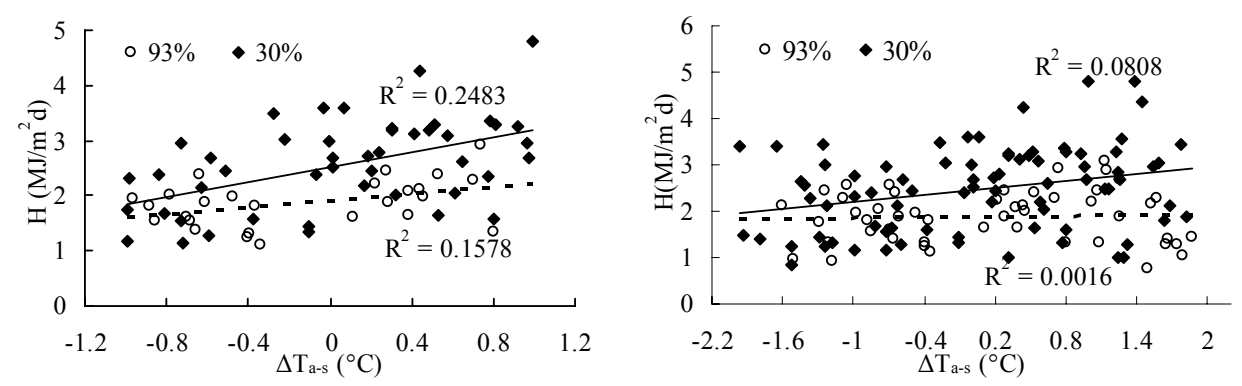

Fig. 9. Relationship between the soil-air temperature difference $\left(\Delta T_{a-s}\right)$ and soil moisture content $\left(\theta_{v}\right)$ for alpine meadow soils of the Qinghai-Tibet Plateau under different levels of vegetation cover.
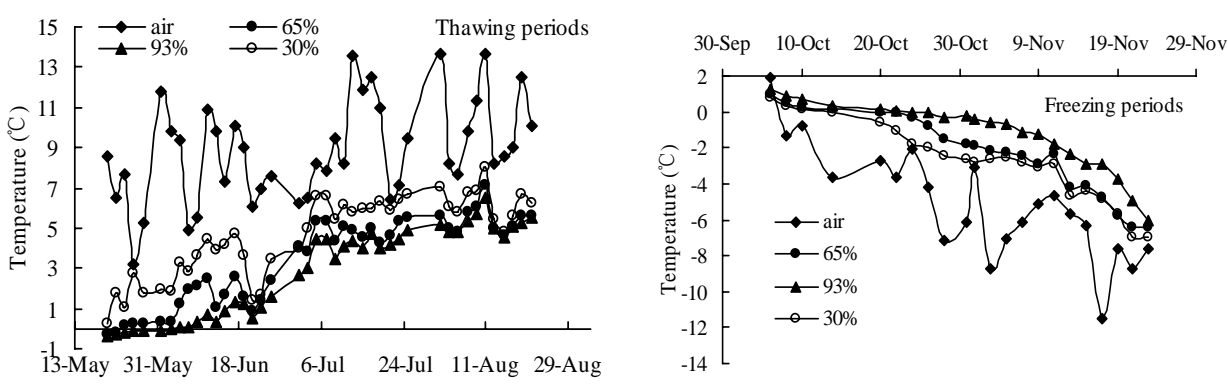

Fig. 10. Dynamic changes in soil temperature with air temperature measured in the 0-20 layer under different levels of vegetation cover during the thawing and freezing processes.

late June. Figure 10 shows that the maximum frozen depth reached to $190 \mathrm{~cm}$ and $120 \mathrm{~cm}$ depth in late November under $30 \%$ and $93 \%$ vegetation cover, respectively. At late August, the maximum thawing depth may reach to about $195 \mathrm{~cm}$ and $220 \mathrm{~cm}$ under $93 \%$ and $30 \%$ vegetation cover, respectively.

\section{Discussion}

It should be noted that the factors affecting the soil water-heat relationship in the active layer are complex; in particular, the vegetation cover, snow cover, water regime, and soil structure and composition all have significant effect on the relationship (Smith and Riseborough, 1996; Wang et al., 2001a). Smith and Riseborough $(1996,2002)$ developed the TTOP model to analyze the effects of vegetation, snow cover, and soil properties on the temperature of permafrost. According to their model, if the effect of snow cover is absent, the vegetation cover showed a positive influence on soil temperature. The permafrost preservation by the surface vegetation cover and organic layer had been reported in the boreal forest of northern Canada and interior Alaska (Yoshikawa et al., 2003; Shur and Jorgenson, 2007). For the boreal-forestcovered permafrost area, it was suggested that the organic and fine-grained soils and the surface litter layer had generally low thermal conductivity (Fukui et al., 2008; Shur and Jorgenson, 2007; Williams and Burn, 1996). The results presented here also verify these findings in the alpine-meadow- covered permafrost area of Tibet Plateau. As the vegetation cover in the studied alpine meadow decreased due to degradation, the content of coarse grains in the surface soil layer would be increased, and organic matter content would decrease. Thus, soil heat conductivity and heat capacity would be correspondingly enhanced. Furthermore, the increase in the heat content of the deep soil layer would lead to an increase in the thawing depth. In Canada, Yi et al. (2007) found that the occurrence of vegetation and extensive presence of a peat and organic layer in circumpolar areas will significantly modulate the regional impact of climate warming on permafrost thaw. The variation of heat balance and soil surface heat flux entered into or left from soil was significant with different vegetation cover and in different seasons. That was the main factor that caused the variation of the soil temperature and moisture under different vegetation covers.

In the permafrost region, the heat transmission and soil temperature gradient controlled the soil water profile distribution during freezing and thawing processes (Zhou et al., 2000; Zhang et al., 2003). The findings of this study indicated that soil freezing and thawing temperatures are related to soil moisture content, grain size composition, soil structure, and organic matter content; these soil properties vary with changes in vegetation cover. Thus, the influences of changes in vegetation cover on the soil water and heat coupling regimes of an alpine meadow are manifest in two mechanisms: 1) vegetation directly affects the transmission 

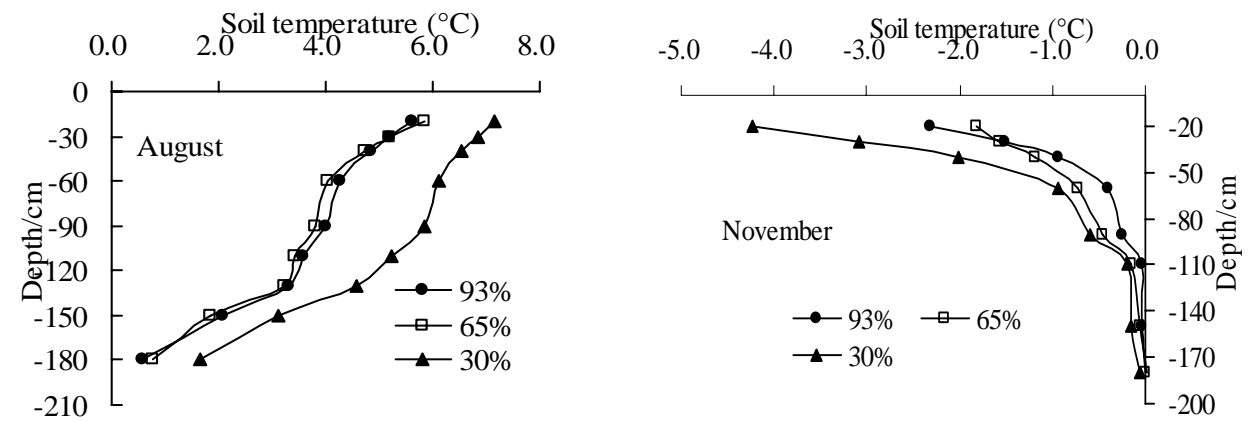

Fig. 11. The soil temperature distribution in active profile in thawed period (August) and frozen period (November) under different vegetation covers.

of water and heat, 2) vegetation indirectly affects the transmission of water and heat via the changes in physicochemical properties of the soil. With climate warning, the permafrost degradation caused the vegetation cover to decrease via drying in active soil, which inversely enhances the permafrost degradation in the Qinghai-Tibet Plateau. Finally, the land surface tends to undergo desertification. 3) not only under different vegetation type, there were different soil water and heat coupling model, but also the model varied under the vegetation cover changes within same vegetation type. Furthermore, in soil thawing and freezing processes, there were different $\theta_{v}-T_{s}$ coupling model.

Under vegetation degradation, the soil $\theta_{v}-T_{S}$ coupling relationship variaitons consequentially caused the landsurface water regime changes. In the sub-arctic permafrost region of northeastern Mongolia, Zhang et al. (2005) found that the tendency of topsoil layer becoming dry under vegetation cover diminished as soil temperature increased. The findings are similar to the results of this study. However, contrast to the situation in the permafrost area in the Qinghai-Tibet Plateau, the permafrost degradation studied by Jorgenson et al. (2001) indicated that the permafrost degradation resulted in an obviously colonization of wetland and aquatic foliage in the birch forest area of central Alaska. Thus, there are different responses of soil water and vegetation cover to permafrost degradation under climate warming in different permafrost region.

\section{Conclusions}

Degradation of the alpine meadow resulted in an increase in the soil thawing temperature, an increase in soil thawing depth, and a tighter response of $T_{s}$ to changes in $T_{a}$. The surface heat flux and soil heat storage in the upper $20 \mathrm{~cm}$ layer increased with increasing vegetation cover, while the downward transmitted heat flux decreased. The greater the vegetation cover, the greater the heat-insulating effect of the surface soil layer, which acted to reduce both the upward heat flux during the period of frozen soil and the downward heat flux during the thawing process. This finding indicates that healthy vegetation within alpine meadows in the permafrost region provides excellent heat insulation. The maintenance of a high vegetation cover of alpine meadows is favourable to slow down the heat cycling of the permafrost, and minimize the impact of climate warming on the permafrost. Hence, protection of alpine meadows is important in maintaining the stability of engineering works constructed within frozen soil on the Qinghai-Tibet Plateau.

Changes in vegetation coverage upon the studied alpine meadow had a significant effect on the coupling relationship of $\theta_{v}$ and $T_{s}$. When the vegetation of such meadows is degraded and vegetation cover was reduced, clear changes are observed in the $\theta_{v}-T_{s}$ relationship. For a given $T_{s}, \theta_{v}$ increased with increasing vegetation cover. Alpine meadow soils under a high vegetation cover exhibit a high waterstorage capacity during the freezing process. This water accumulates in the root zone $(0-0.20 \mathrm{~m})$ during the thawing process, and thereby favours the growth of vegetation in alpine meadows. When vegetative cover decreased, soil water circulation in the active layer increased, and the response to temperature of the water distribution across the soil profile was heightened. Comparing with the situation in central Alaska, where the permafrost degradation resulted in the development of the wetland area and aquatic herbaceous under warming climate change, the permafrost degradation in the Qinhai-Tibet Plateau caused the land surface to become drier and more prone to desertification.

Acknowledgements. This study was funded by the national key scientific plan (973) (No. 2007CB411504), the Natural Science Foundation of China (No. 40730634) and the "Hundred People" Project of the Chinese Academy of Science. The authors thank the anonymous reviewers for their fruitful comments, and help in improving the presentation of this research.

Edited by: N. Romano 


\section{References}

Bakalin V. A. and Vetrova V. P.: Vegetation-Permafrost relationships in the zone of sporadic permafrost distribution in the Kamchatka Peninsula, Russian Journal of Ecology, 39(5), 318-326, 2008.

Bubier, J. L., Frolking, S., Crill, P. M., and Linder, E.: Net ecosystem productivity and its uncertainty in a diverse boreal peatland, J. Geophys. Res., 104(D22), 27683-27693, 1999.

Carey S. K. and Woo M. K.: Hydrology of two slopes in subarctic Yukon, Canada, Hydrol. Process, 13, 2549-2562, 1999.

Cheng, G.: Problems on zonation of high altitude permafrost. Acta Geographica Sinica, 39(2), 185-193, 1984.

Chen, R., Lu S. H., and Kang E. S.: A distributed water-heat coupled (DWHC) model for mountainous watershed: model structure and equations. Adv. Earth Sci., 21(8), 806-818, 2006.

Christensen T. R., Johansson T., and Kerman H. J.: Thawing subarctic permafrost: Effects on vegetation and methane emissions, Geophysi. Res. Lett., 31, L04501, 2004.

Flerchinger, G. N.: The Simultaneous Heat and Water (SHAW) Model: User's Manu, Technical Report NWRC, 2000-10, 2000.

Eugster,W., Rouse,W., Pielkesr, R. A.,Mcfadden, J. P., Baldocchi, D. D., Kittel, T. G. F., Chapin, F. S., Liston, G. E., Vidale, P. L., Vaganov, E., and Chambers, S.: Land-atmosphere energy exchange in Arctic tundra and boreal forest: available data and feedbacks to climate, Global Change Biol., 6 (suppl. 1), 84-115, 2000.

Jansson, P.-E. and Karlberg, L.: COUP manual Coupled heat and mass transfer model for soil-plant-atmosphere systems, online available at: http://www.lwr.kth.se/varadatorprogram/ CoupModel/, 2001.

Jayawickreme, D. H., Van Dam, R. L., and Hyndman, D. W.: Subsurface imaging of vegetation, climate, and rootzone moisture interactions, Geophys. Res. Lett., 35, L18404, doi:10.1029/2008GL034690, 2008.

Jorgenson, M. T., Racine, C. H., Walters, J. C.: Permafrost degradation and ecological changes associated with a warming in central Alaska, Clim. Change, 48, 551-579, 2001.

Kang, E., Cheng, G. D., and Song, K. C: Simulation of energy and water balance in Soil-Vegetation-Atmosphere Transfer system in the mountain area of Heihe river basin, China. Science in China (Series D), 48(4), 538-548, 2005.

Legates, D. R. and McCabe, G. J.: Evaluating the use of "goodnessof-fit" measures in hydrologic and hydro-climatic model validation, Water Resour. Res. 35(1), 233-241, 1999.

Ma, Y., Yao, T., Wang, J., and Hu, Z.: The Study on the Land Surface Heat Fluxes over Heterogeneous Landscape of the Tibetan Plateau, Adv. Earth Sci., 21(12), 1215-1224, 2006.

McGuire, A. D.: Environmental variation, vegetation distribution, carbon dynamics and water/energy exchange at high latitudes, Journal of Vegetation Science, 13(1), 301-314, 2002.

Mayocchi, C. L. and Bristowa, K. L.: Soil surface heat flux: some general questions and comments on measurements, Agr. For. Meteor., 75, 43-50, 1995.

Ministry of Agriculture of China Technical specifications of soil analysis, Beijing, Chinese Agriculture Press, 14-172, 1993.

Nash, J. E. and Sutcliffe, J. V.: River flow forecasting through conceptual models, 1, discussion of principles, J. Hydrol., 10, 282292, 1970.

National Soil Survey Office (NSSO), Soil of China, China Agricul- ture Press, Beijing, China, 1998.

NWRC SHAW (Vol.2.3.6), http://www.nwrc.ars.usda.gov/Models/ SHAW.html, 2004.

Oechel, W. C., Vourlitis, G. L., Hastings, S. J., Zulueta, R. C., Hinzman, L., and Kane, D.: Acclimation of ecosystem CO2 exchange in the Alaskan Arctic in response to decadal climate warming, Nature, 406, 978-980, 2000.

Payero, J. O., Eale, C. M. U., Wright, J. L., and Allen, R. G.: Guidelines for validating Bowen Ratio data, Transactions of the ASAE, 46(4), 1051-1060, 2003.

Rouse, W. R.: Progress in hydrological research in the Mackenzie GEWEX study, Hydrol. Proc., 14, 1667-1685, 2000.

Sato, T.: Spatial and temporal variation of frozen ground and snow cover in the eastern Tibetan Plateau, J. Meteor. Soc. Jpn., 79, 519-534, 2001.

Smith, M. W. and Riseborough, D. W.: Ground temperature monitoring and detection of climate change, Permafrost Periglac., 7(4), 301-310, 1996.

Smith, M. W. and Riseborough, D. W.: Climate and the limits of permafrost: a zonal analysis, Permafrost Periglac., 13(1), 1-15, 2002.

Gu, S., Tang, Y. H., Cui, X. Y., Kato, T., Du, M. Y., Li, Y. N., and Zhao, X. Q.: Energy exchange between the atmosphere and a meadow ecosystem on the Qinghai-Tibetan Plateau, Agr. For. Meteor., 129, 175-185, 2005.

Turetsky, M. R., Kelman Wieder, R., and Vitt, D. H.: Boreal peatland $\mathrm{C}$ fluxes under varying permafrost regimes, Soil Biol. Biochem., 34, 907-912, 2002.

Walker, D. A., Jia, G. J., and Epstein, H. E.: Vegetation-soilthaw-depth relationships along a low-arctic bioclimate gradient, Alaska: synthesis of information from the ATLAS studies, Permafrost Periglac., 14, 103-123, 2003.

Wang, G., Li, Q., Cheng, G. D., and Sheng, Y. P.: Climate change and its impact on the eco-environment in the source regions of Yangtze and Yellow Rivers in recent 40 years, J. Glac. Geocry., 23(4), 346-352, 2001a.

Wang, G., Cheng, G. D., and Shen, Y. P.: Research on ecological environmental changes in Yangtze and Yellow Rivers source regions and their integrated protection (in Chinese), 213 pp., Lanzhou University Press, Lanzhou, China, 2001b.

Wang, G., Ding, Y. J., Wang, J., and Liu, S. Y.: Land ecological changes and evolutional patterns in the source regions of the Yangtze and Yellow Rivers, Acta Geographic Sinica, 15(2), 163173, 2004.

Weller, G., Chapin, F. S., Everett, K. R., and Hobbie, J. E.: The arctic FLUX study: a regional view of gas release, J. Biogeogr., 22, 365-374, 1995.

Wu, Q. and Liu, Y. Z.:: Ground temperature monitoring and its recent change in Qinghai-Tibet Plateau, Cold Reg. Sci. Technol., 38, 85-92, 2004.

Wu, Q. B., Shi, B., and Liu, Y. Z.: Research on the interaction of permafrost and highway along Qinghai-Tiber highway, Science in China (Series D), 32(6), 514-520, 2002.

Xu, X., Wang, J. C., and Zhang, L. X.: Permafrost physics (in Chinese), Science Press, Beijing, 310 pp. 2001.

Yi, S., Arain, M. A., and Woo, M. K.: Modefications of a land surface scheme for improved simulation of ground freeze-thaw in northern environments, Geophys. Res. Lett., 33, L13501, doi:10.1029/2006GL026340, 2006. 
Zhang, Y., Ohata, T., and Kadata, T.: Land surface hydrological processes in the permafrost region of the eastern Tibetan Plateau, J. Hydrol., 283, 41-56, 2003.

Zhang, Y., Munkhtsetseg, E., Ohata, T., and Kadata, T.: An observational study of ecohydrology of a sparse grassland at the edge of the Eurasian cryosphere in Mongolia, J. Geophys. Res., 110, D14103, doi:10.1029/2004JD005474, 2005.
Zhou, Y., Guo, D. X., Qiu, G. Q., and Cheng, G. D.: Geocryology in China (in Chinese), Science Press, Beijing, China, 450 pp., 2000.

Zhou, X. M.: Chinese Kobresia pygmaea meadow (in Chinese), Science Press, Beijing, China, 370 pp., 2001. 